$1 / \gamma^{8} / 8^{\circ}$ LA-8440-MS mint

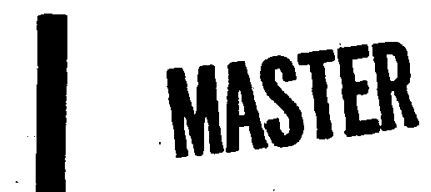
Uranium, Thorium, and Lead Migration at Key Lake, Saskatchewan, Canada

An Interim Report on Studies of

은

$\frac{2}{\infty}$

$\frac{5}{5}$ 
LA-8440-MS

Informal Report

UC-51

Issued: Suly 1980

\section{An Interim Report on Studies of \\ Uranium, Thorium, and Lead Migration at \\ Key Lake, Saskatchewan, Canada}

David B. Curtis

A. J. Gancarz
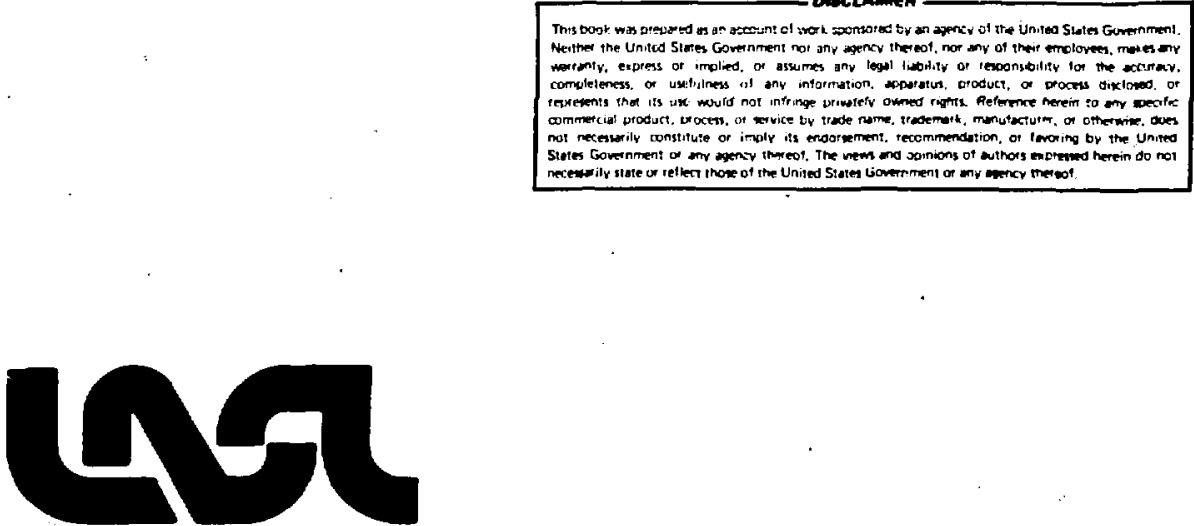

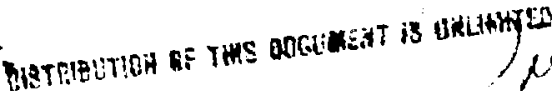




\begin{abstract}
AN INTERIM REPORT ON STUDIES OF URANIUM, THORIUM, AND LEAD MIGRATION AT KEY LAKE, SASKATCHEWAN, CANADA
\end{abstract}

by

David B. Curtis and A. J. Gancarz

\title{
ABSTRACT
}

The redistribution of uranium, thorium, and lead is being examined in sanples representing several million cubic meters of sandstone and metamorphased sediments in the Athabasca Basin which is located in the northwest corner of the Canadian province of Saskatchewan. The region of study includes zones of uranium mineralization at Key Lake. Mineraization occurs at the unconformity between the Athabasca sandstone and the underlying metasediments and in fault zones within the metasediments.

Lead isotopes record a radiometric age of $1300 \pm$ $150 \mathrm{~m} . \mathrm{y}$. in samples from above and below the unconformity. This age probably reflects the time of deposition of the sandstones and an associated redistribution of uranium and/or lead in the underlying rocks. Many of the samples have been fractionated with respect to radiogenic lead and the actinide parent elements since that time. Sandstones and altered rocks from the region above the unconformity have been a transport path and a re a repository for lead. In contrast, mineralized rocks are deficient in radiogenic lead and must be an important source of lead in the local geologic environment. However, the isotopic composition of lead missing from the ores is different from that found in the overlying sandstones. The two types of rocks do not appear to represent complements with respect to source and a repository for lead. 


\section{CONTENTS}

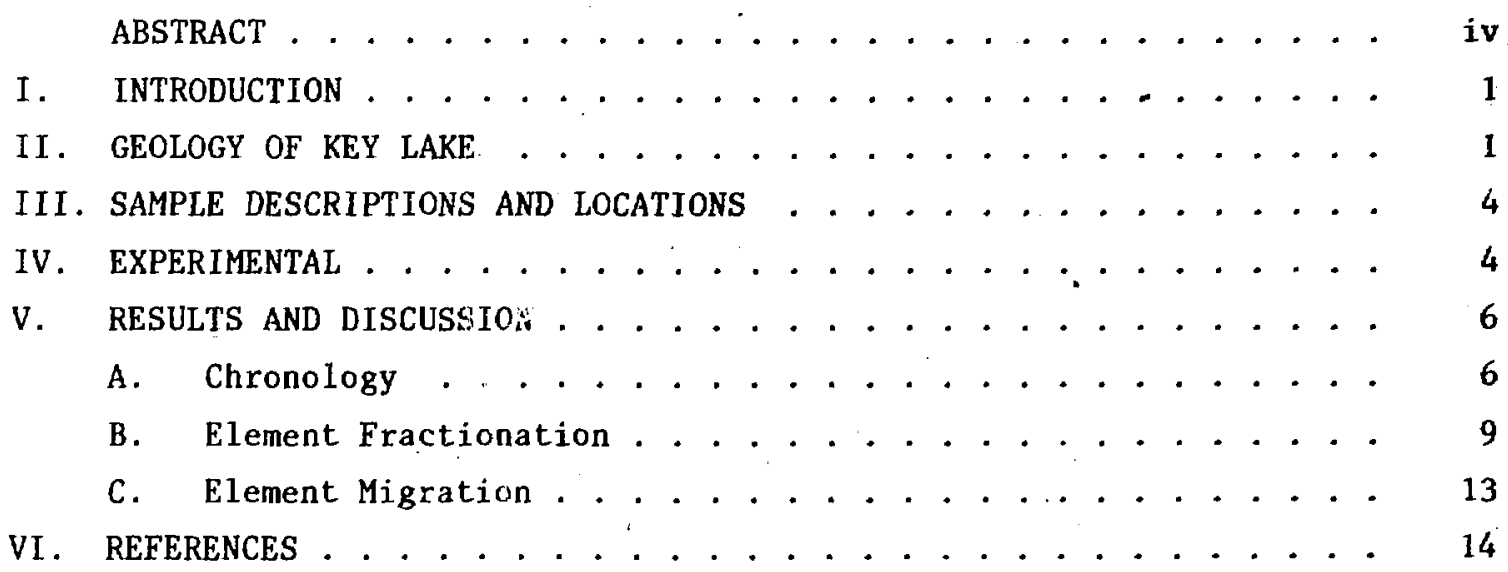




\section{INTRODUCTION}

Uranium and thorium decay through a series of radionuclides to form stable isotopes of lead. The radioactive decay law predicts the relative proportions of actinide parent and stable lead daughter in a rock that has been chemically stable through a particular time interval. Present abundances of lead isotopes in natural materials depend upon the duration of this interval, the relative abundances of thorium, uraniun, and lead in the rock when it was formed (the initial concentration), and the isotopic composition of the initial lead. In principal, chemical and isotopic analyses of rocks for these three elements provide the means to understand aspects of the natural history of the rocks, i.e. when they were formed, the chemical history prior to their formation, chemical alterations after their formation, enrichments of one element relative to another, when the element fractionation occurred and the nature of the physical and chemical processes involved in the fractionation, transport, and redeposition of these components.

The Key Lake deposit is one of several rich uranium deposits discovered in the Athabasca Basin in the northwest corner of the Canadian province of Saskatchewan. It offers an excellent set of circumstances for the study of the retention and migration of uranium, thorium, and lead over geologic periods of time. Ores containing large quantities of uranium and lead are confined in host rocks that have "normal" quantities of these elements. Because of the extraordinary composition of the ores, the lead isotopic composition is significantly different than that of lead formed in-situ in the country rocks. This disparity provides a means of identifying mixtures of lead that originated in different sources.

Drill cores, taken as part of the exploration program, have provided well documented samples from the mineralized region. These samples, which include ores and unmineralized host rocks are being analyzed for lead, uranium, and thorium concentrations and lead isotopic abundances. The goal of the study is to understand the chronology of the rocks, assess the extent of uranium and lead migration, identify sources, transport paths and repositories for these elements and try to understand the mechanisms involved in the processes.

\section{GEOLOGY OF KEY LAKE}

Key Lake is located on the southeastern edge of the Athar:sca Formation, a fluviatile, quartz sandstone deposit. The age of this deposit has been 
determined to be $1350 \pm 50 \mathrm{~m} . \mathrm{y}$. by $\mathrm{Rb} / \mathrm{Sr}$ dating (Raemaekers and Dunn, 1976) and $1330 \pm 30 \mathrm{~m} \cdot \mathrm{y}$. from $\mathrm{Pb}$ isotopic data (Gancarz, 1978). The Athabasca sandstone unconformably overlays rocks of the Wollaston Domain, a major structural province of the Canadian shield. The highly deformed basement complex consists of synforms and antiforms with granitoid Archean cores rimmed by Proterozoic metasediments. (Hoeve and Sibbald, 1978). Radiometric dating of the granitoid basement show it to be at least $2.5 \times 10^{9}$ years old. Multiple periods of metamorphism are observed in the metasediments. The major metamorphic period occurred about $1.7 \times 10^{9}$ years ago with episodes as recently as $1.57 \times 10^{9}$ years (Cummings and Scott, 1976; Money, 1968). The entire region is overlain by Pleistocene glacial debris.

The rocks of the basement complex at Key Lake are graphitic metapelites which comprise the basal section of the Proterozoic sedimentary sequence. (Hoeve and Sibbald, 1978). The major rock type is a biotite-feldspar-cordierite gneiss (Dahlkamp, 1978) which probably represents upper amphibolite facies metamorphism associated with early deformational events (Hoeve and Sibbald, 1978). This gneiss is altered in the vertical section. The degree of alteration decreases with vertical distance away from the unconformity. Dahlkamp (1978) attributes this alteration to weathering of the paleosurface. A graphite-chlorite-sericite schist grades with depth into a graphite schist. The graphite content is as high as 45 volume percent in this latter rock type (Dahlkamp, 1978). These schists represent retrograde metamorphism perhaps associated with later events in the deformation of the Wollaston Domain (Hoeve and Sibbald, 1978). Coarse grained pegmatoid rocks in the basement contain residual metamorphic minerals. Dahlkamp (1978) suggests that these are anatectic rocks associated with the upper amphibolite metamorphism.

Rocks of the Athabasca Formation consist predominantly of quartz with traces of kaolinite, sericite and chlorite. Apatite, tourmaline zircon, and opaque minerals occur as accessories. A minor quartz pebble conglomerate is found at the base of the sandstone formation. There is a transition zone between this basal conglomerate and the basement. Lithogically the zone resembles the Athabasca sandstone. However, there is a decrease in quartz and an increase in phyllosilicates with depth, grading into the crystalline basement rocks. Dahlkamp and Tan (1977) refer to this as a region of static chemical alteration and suggest that it was weathered section at the 
paleosurface now represented by the unconformity. Hoeve and Sibbald (1978) indicate that this altered section at the unconformity has many of the characteristics of modern laterites.

Pre and post Athabasca faults are important structural features at Key Lake. They trend northeast-southwest and dip at $50^{\circ}$ to $70^{\circ}$ to the northwest, roughly parallel to the stratigraphic dip of the basement metasediments. Dahlkamp (1978) identifies three rock types associated with the structural disturbances. A kaolinite mylonite, contains no chlorite or sericite and is in places is pure kaolinite. Iron rich chlorite is the major mineral in a chlorite mylonite. Sericite-chlorite mylonite contains Mg-rich chlorite derived from biotite and cordierite. This rock type probably represents alteration of the abundant feldspar-biotite-cordierite gneiss. Dahlkamp (1978) suggests that chemical alteration of the latter rock predates the process of mylonization.

The two Key Lake ore bodies are localized in fault zones which appear to impose a structural control on the mineralization. The kaolinite mylonite and Fe-rich chlorite mylonite are the principal hosts for the ore minerals. Mineralization is negligible in the Mg-chlorite-sericite mylonite. Mineralization at the northeast portion of the fault zone, the Dielmann orebody, is the subject of this study. Ore at Dielmann occurs at the unconformity for . distances of about 100 meters to the southeast of the faulted region. It extends 150 meters into the basement along the dip of the fault zone The Athabasca sandstone that immediately overlays the ores is 40-60 meters thick. To the northeast, at distances between 30 and 100 meters, the sandstone thins dramatically occasionally having thicknesses of less than 5 meters.

Uranium and nickel are the major metallic elements in the ores, with smaller abundances of lead, zinc, and copper. Concentrations of the two wajor elements often run into the tens of percent. Three uranium minerals have been identified (Dahlkamp, 1978). An oxide called pitchblende I, a more oxidized variety of pitchblende, called sooty pitchblende or pitchblende II, and the silicate mineral coffinite. The arsenosulfide gersdorfite is the most abundant nickel mineral with nickel arsenides and sulfides also being prominent phases. Galena is ubiquitous throughout the ores. 


\section{SAMPLE DESCRIPTIONS AND LOCATIONS}

Table I contains brief descriptions of the samples that have been analyzed. Also included in this Table are approximate distances from the nearest ore bearing regions. Locations of material that resided at or above the unconformity are oriented relative to the contact between the sandstone and the basement and to the nearest ore that occurs at the contact. Basement rocks are oriented by distance downdip from the nearest ore bearing basement rocks and through the stratigraphic section relative to the principal ore bearing strata.

Samples taken from above the uncomformity represent a maximum horizontal separation of 300 meters in a north-south sense and 500 meters in an east-west sense. Samples KL-12 and KL-1 are the samples of sandstone furthest removed from uranium rich regions. Samples $K L-10$ and $K L-15$, and $K L-11$ and $K L-13$, are each a pair of samples separated from one another vertically in the same core. The sample identified as KL-25 was taken from the basement near Zimmer Lake, a region well removed from known mineralization, about $5 \mathrm{~km}$ to the southwest of Key Lake. It was analyzed to provide reference data for basement rocks.

\section{EXPERIMENTAL}

Approximately ten grams of rock were extracted from the interior of core sections chosen for analysis. These interiors were crushed and seived through 100 mesh screens. One gram aliquots were taken for determination of uranium and thorium concentrations. Concentrations of these two elements were determined by neutron activation analysis techniques using the automated analysis system at the Los Alamos Omega West Reactor. Uranium is analyzed by irradiating with thermal neutrons and measuring the delayed neutrons emitted from the decay of the neutron rich products of the fission of ${ }^{235} \mathrm{U}$. Concentrations are determined by direct comparison with a standard of known uraniun concentration. After appropriate periods of thermal neutron irradiation and decay of potentially interfering radioactive nuclides, Th is detected by measuring the $311.9 \mathrm{Kev}$ gama-ray enitted by ${ }^{233} \mathrm{~Pa}$. This nuclide is the daughter of ${ }^{233} \mathrm{Th}$ which is produced in the reactor by ${ }^{232} \operatorname{Th}(n, y)^{233} \mathrm{Th}$.

Lead isotope abundances are measured by isotope dilution mass spectrometry on 200 to $500 \mathrm{mg}$ aliquots of the powdered samples. Samples are dissolved by an $\mathrm{HF}-\mathrm{HC}_{4}$ acid dissolution technique. A measured aliquot of the sample solution is added to a known quantity of standardized ${ }^{208} \mathrm{~Pb}$ and lead is separated from the solution. Ratios of the lead isotopes are measured on a 12 " 
TABLE I

DESCRIPTION OF KEY LAKE SAMPLES

SAMPLSS AT OR ABOVE THE UXCONFORMITY

\begin{tabular}{|c|c|}
\hline Secole Ho. & Description \\
\hline $\mathbf{K L}-\mathbf{1}$ & Sandatone \\
\hline $\boldsymbol{x} \mathbf{l}-7$ & Sandstone \\
\hline XL-8 & Sandstone \\
\hline $\boldsymbol{x} \boldsymbol{L}-9$ & - Sandstone \\
\hline $\mathbf{L L}-10$ & Sandstone \\
\hline $\mathbf{x L}-11$ & Sandstone \\
\hline$x L-12$ & Sandstone \\
\hline $\mathbf{X L}-1 \mathbf{6}^{\circ}$ & Sundstone \\
\hline $\mathbf{K L}-13$ & Pyrite bearing contact \\
\hline$x-15$ & Oxidized contact \\
\hline
\end{tabular}

\begin{tabular}{c} 
Distance Above Unconforwity \\
(Meters) \\
\hline 40 \\
10 \\
5 \\
55 \\
45 \\
25 \\
2 \\
2 \\
0 \\
0
\end{tabular}

Stratigraphic Distance From Ore Bearing Zone (Heters)

Sample 10.

xL-19

$\mathbf{x L}-20$

KL-21

XL-16

LL-17

KL-18

RL-2

KL -25

sayptes or cre

Sacole No.

KL-3

$\boldsymbol{1}$
Description

\section{Graphic sneiss}

Qustz from quartz.vein

Contact between KL-20 and basement rock

Pyrite bearins contact between $\mathrm{KL}-17$ and $\mathrm{KL}-18$

Quartz from quartz vein

Dasement rock $10 \mathrm{~cm}$ from KL-17

Quartz-biotite-feldspar eneiss

Pyrite bearing bastement
Horizontal Distance From Nearest Ore (Meters)

180

10

35

10

150

10

70

Dowadip Distance From Nearest Ore (Heters)

$\begin{array}{rr}+45 & 0 \\ +45 & 0 \\ +40 & 0 \\ -15 & 0 \\ -15 & 0 \\ -15 & 0 \\ -30 & 140\end{array}$

Saaple Taken at Ziber Lake $55 k$ from Key lake Deposit:

0
0
0
0
0
0
40
Deposit:


radius of curvature, solid source mass spectrometer. The identical analysis is done on another aliquot of the sample to which no calibrated ${ }^{208} \mathrm{~Pb}$ is added. Data from the two analyses provide the means to calculate the abundance of each lead isotope, and hence the element abundance, in the rock.

Our procedure to separate lead from the sample has been adapted from techniques used at other laboratories. The sample solution is made $1 \mathrm{~N}$ in $\mathrm{HBr}$, and the lead bromide complex is isolated from this solution by anion exchange (Chen, 1979). The element is subsequently eluted from the anion resin with 10N HC1. Final preparation for mass spectrometry is accomplished by anodic deposition of $\mathrm{PbO}_{2}$ from a dilute solution of $\mathrm{HClO}_{4}$ (Barnes et al., 1972). Weighed aliquots of the ${ }^{208} \mathrm{~Pb}$ calibrated spike were routinely put through the chemical separations to measure the quanitity of lead introduced by the procedures (blanks). These blanks varied from 2 to 6 nanograms of lead with "common" isotopic composition. All results have been corrected for blank contributions.

Separated lead is mass analyzed by loading on a Re filament with $\mathrm{H}_{3} \mathrm{PO}_{4}$ and silica gel and evaporating to dryness. The sample prepared in this way is loaded in the mass spectrometer and heated to operating temperature through a well defined time and temperature sequence. The NBS lead isotope standard number 982 is regularly analyzed in this way. The results of 10 analyses of this standard are presented in Table II. The results demonstrate the ability to reproduce a value to within 4 parts in 10,000 at the $95 \%$ confidence level. Mass fractionation biases the results relative to the standardized value by 5 to 9 parts in 10,000 per mass unit. This difference in the mass fractionation factors is larger than would be expected from the measurement techniques. It probably reflects difficulty in measuring the minor isotope ${ }^{204} \mathrm{~Pb}$. Differences of this magnitude are not significant to the final results of the experiment. All results have been corrected for mass fractionation using the factor measured by the ${ }^{208} \mathrm{~Pb} /{ }^{206} \mathrm{~Pb}$ ratio.

\section{RESULTS AND DISCUSSION}

A. Chronology

A suite of rocks which had the same lead isotopic composition but different relative quantities of uranium and lead at time $T$ in the past, now contain lead that defines a straight line (an isochron) on a plot of ${ }^{204} \mathrm{~Pb} /{ }^{206} \mathrm{~Pb}$ vs. ${ }^{207} \mathrm{~Pb} /{ }^{206} \mathrm{~Pb}$. The location of a datum on the line is a function of the 
TABLE II

MASS SPECTROMETRIC ANALYSES OF NBS-982

$$
\begin{aligned}
& \text { Average Measured } \\
& \text { Ratio } \pm \sigma \\
& \text { Isotope pair } \\
& { }^{208} \mathrm{~Pb} /{ }^{206} \mathrm{~Pb} \\
& 0.9985 \pm 0.0002 \\
& { }^{207} \mathrm{~Pb} /{ }^{206} \mathrm{~Pb} \\
& 0.46665 \pm 0.00009 \\
& { }^{204} \mathrm{~Pb} /{ }^{206} \mathrm{~Pb} \\
& 0.027247 \pm 0.000006 \\
& \overline{\text { Fractionation Factor }}=\left(\begin{array}{l}
\mathrm{R}_{\mathrm{a}} \\
\overline{\mathrm{R}_{\mathrm{m}}}
\end{array}\right. \\
& \mathbf{R}_{\mathbf{a}}=\text { Absolute Ratio } \\
& R_{\mathrm{m}}=\text { Measured Ratio } \\
& \Delta M=\text { Mass difference of the measured pair. } \\
& +0.83 \pm 0.1 \\
& +0.90 \pm 0.2 \\
& -0.51 \pm 0.1
\end{aligned}
$$

uranium-lead ratio, and the intersection of the line with the ordinate defines T. Figure 1 is a presentation of data from Key Lake on such a lead isotope diagram. The data is given in Table III. With a single exception, non-ore samples form a linear array with an ordinate intercept equilivalent to $\mathrm{T}=$ $1.3 \times 10^{9}$ years. The best linear fit was determined using all the data from unmineralized samples except $\mathrm{KL}-20$ which is clearly displaced from the line defined by the rest of the samples. Data in the linear array include those from Athabasca sandstones, highly altered rocks from the contact zone and metasediments from the basement. This age is the same as that determined for the Athabasca by Raemaekers and Dunn (1976). Presumably it reflects the time of deposition of the Athabasca sediments. Metasediments from deeper in the Wollaston Domain than those found in the basement complex at Key Lake, all have radiometric ages older than $1.56 \times 10^{9}$ years (Cummings and Scott, 1976). It is likely that deposition of the sedimentary overburden established chemical conditions that reset the uranium-lead radiometric clock in the underlying rock.

Although the $1.3 \times 10^{9}$ year age is clearly imprinted on the samples, many of the rocks have been chemically disturbed since that time and/or have 
U-Th-Pb DATA FROM KEY LAKE SAMPLES

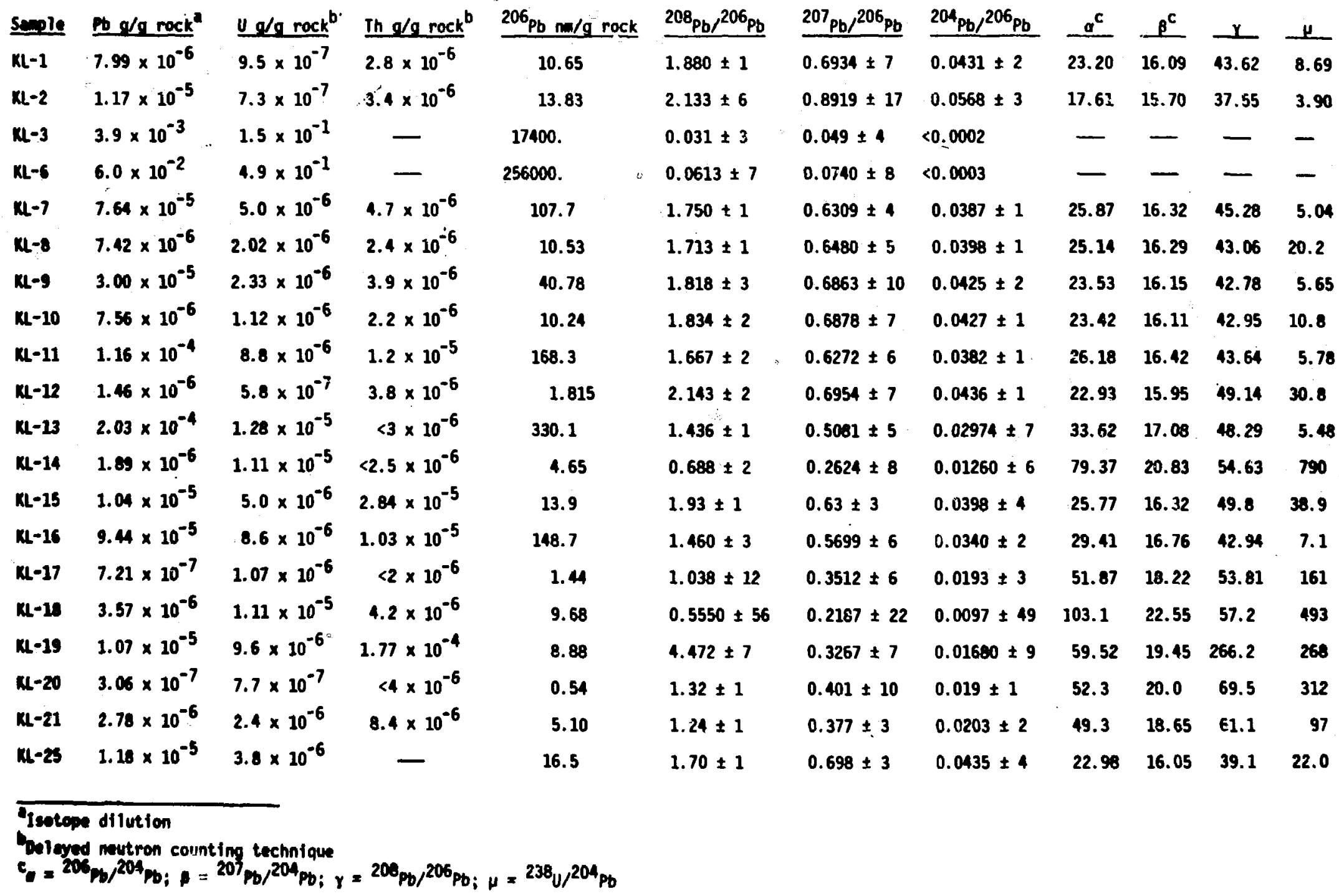


retained isotopic characteristics of previous geologic history. One unmineralized sample obviously falls of $f$ the $1.3 \times 10^{9}$ isochron, however there are several other data points which, although not resolved in Figure 1 , also deviate significantly from perfect linearity. Figure 2 demonstrates these deviations. This Figure was constructed by calculating a value for ${ }^{204} \mathrm{~Pb} /{ }^{206} \mathrm{~Pb}$ (C) from the measured value for ${ }^{207} \mathrm{~Pb} /{ }^{206} \mathrm{~Pb}(\mathrm{M})$ and the parameters from the linear fit to the data. A calculated value is compared with the corresponding measured value by determining the quantity

$$
\zeta=\frac{\left({ }^{204} \mathrm{~Pb} /{ }^{206} \mathrm{~Pb}\right)-\left({ }^{204} \mathrm{~Pb} /{ }^{206} \mathrm{~Pb}\right)_{\mathrm{M}}}{\left({ }^{204} \mathrm{~Pb} /{ }^{206} \mathrm{~Pb}\right)_{\mathrm{C}}} \times 100
$$

This is plotted as a function of the measured ${ }^{207} \mathrm{~Pb} /{ }^{206} \mathrm{~Pb}$ in Figure 2 .

Ten samples from the contact or from the Athabasca formation have values of $\zeta$ that lie within $1 \%$ of the isochron. By contrast five of the eight samples from the basement have $\zeta$ values greater than $1 \%$ including KL-20 for which $\zeta=16 \%$. The envelope in Figure 2 , defined by curves labeled \pm 50 million years, demonstrate the magnitude of deviations from the isochron that would result from the evolution of radiogenic lead during times that differed from $1.3 \times 10^{9}$ years by $\pm 5 \times 10^{7}$ years. These curves were included to demonstrate the magnitude of deviations generated by a very simple scenario.

Two samples of ore yield data that plot near the ordinate and below the linear fit to the non-ore data in Figure 1. The lead in these ores is almost entirely radiogenic and have isotopic compositions that could only have evolved in closed systems from the decay of uranium over periods of time significantly less than $1.3 \times 10^{9}$ years.

B. Element Fractionation

If the rocks at Key Lake had a uniform lead isotopic composition $1.3 \times 10^{9}$ years ago and there had been no uranium-lead fractionation in the meantime, the abundances of ${ }^{206} \mathrm{~Pb}$ relative of ${ }^{238} \mathrm{U}$ are simply defined by equation (2).

$$
\left({ }^{206} \mathrm{~Pb} /{ }^{204} \mathrm{~Pb}\right)_{0}=\left({ }^{206} \mathrm{~Pb} /{ }^{204} \mathrm{~Pb}\right)_{\mathrm{I}}+\left({ }^{238} \mathrm{U} /{ }^{204} \mathrm{~Pb}\right)_{\mathrm{o}}\left(\mathrm{e}^{\lambda \mathrm{T}}-1\right)
$$

the superscript o refers to present observed element and isotope ratios, and $I$ refers to the isotopic ratio in the rock when it was formed. Figure 3 is a 


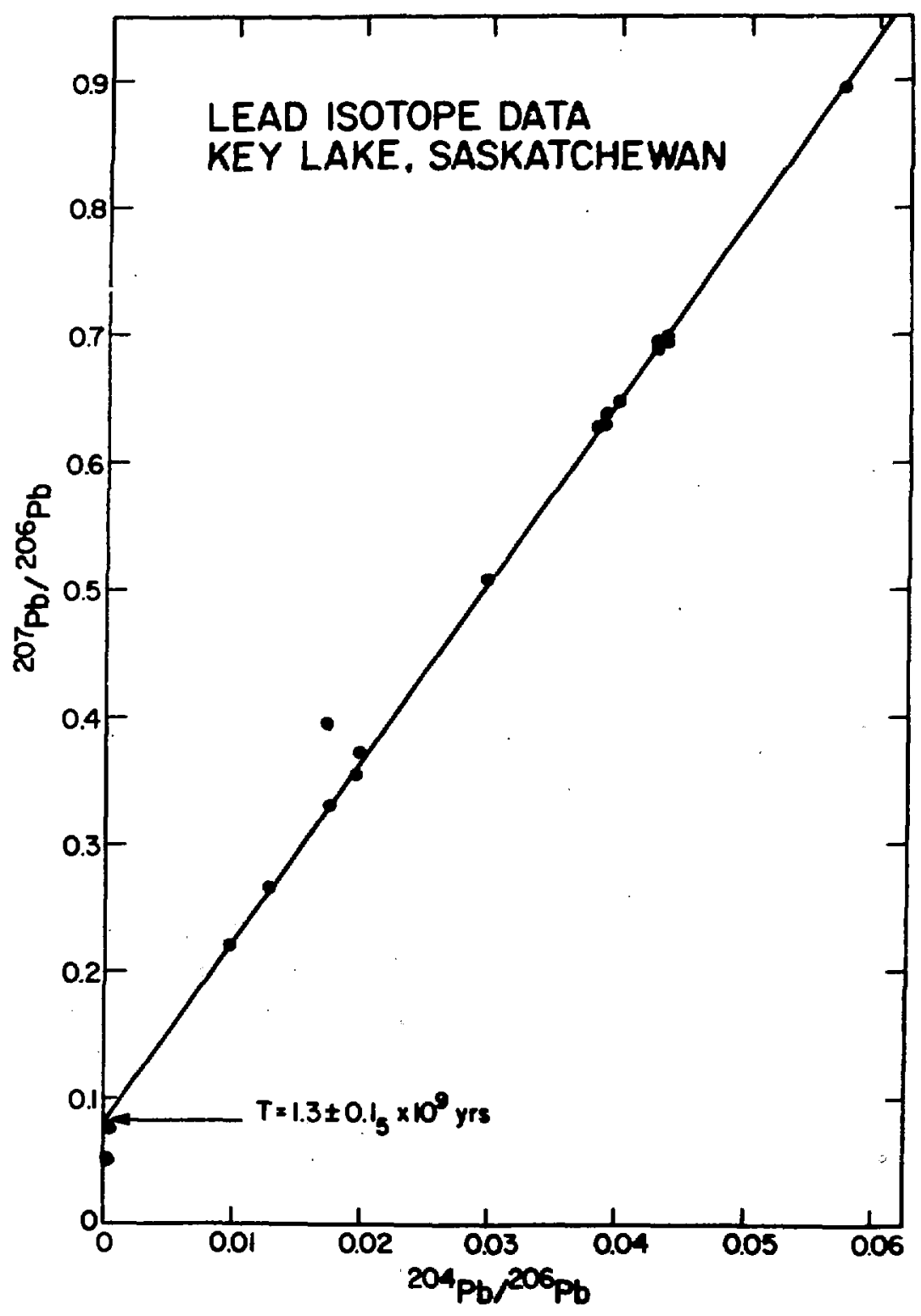

Fig. 1. Lead isotope diagram ahowing the linear array defined by nost of the unineralized rocks. The saple that lies distinctly above the linear array is quartz from a vein in the Rey Lale basement conplex. The two points near the ordinate are uranium rich ores. 


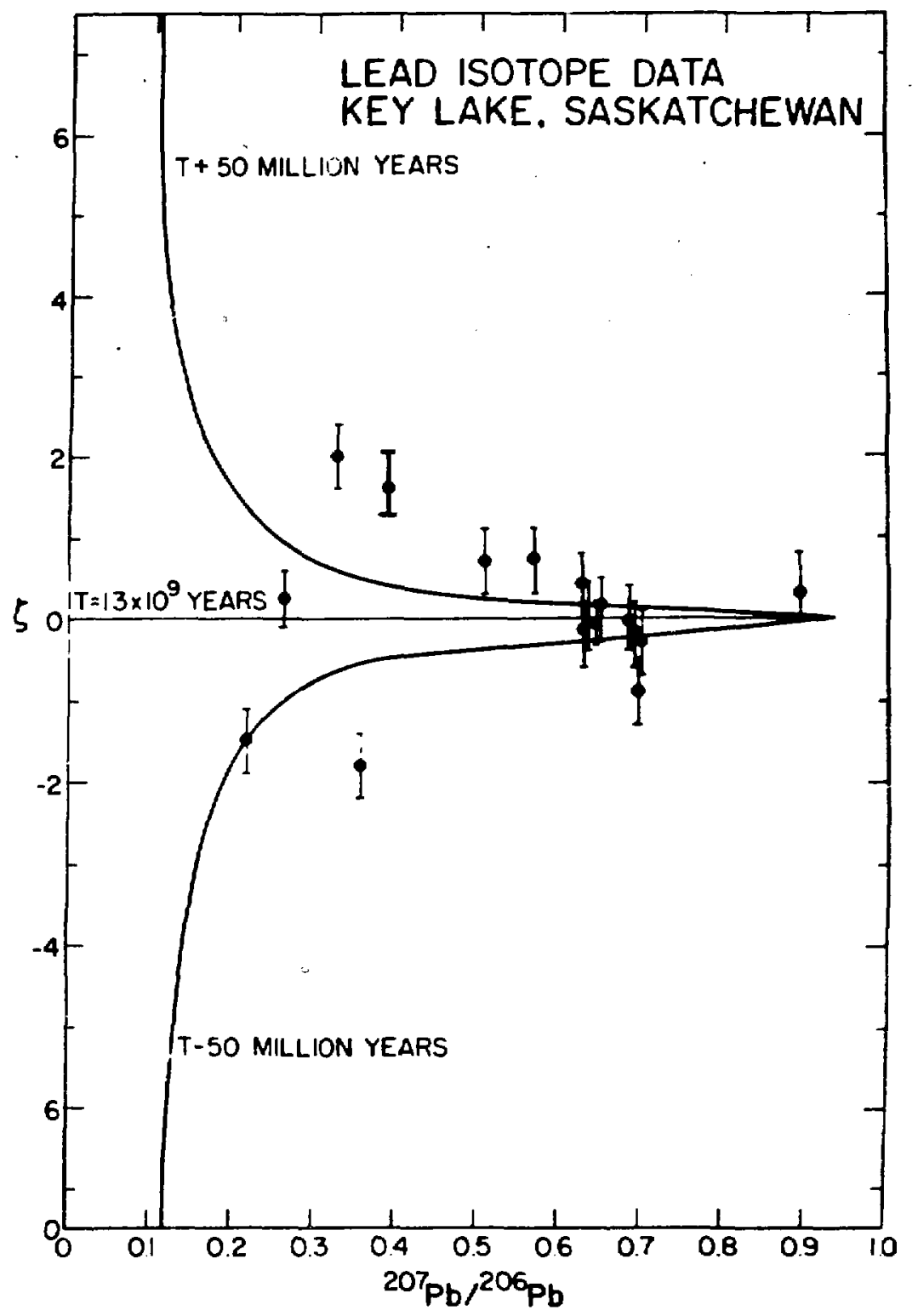

Fig. 2. A diagram showing the deviation of datum from the best linear fit to the data in Figure 1. The four samples with the largest deviation are from below the Athabasca Unconformity. 


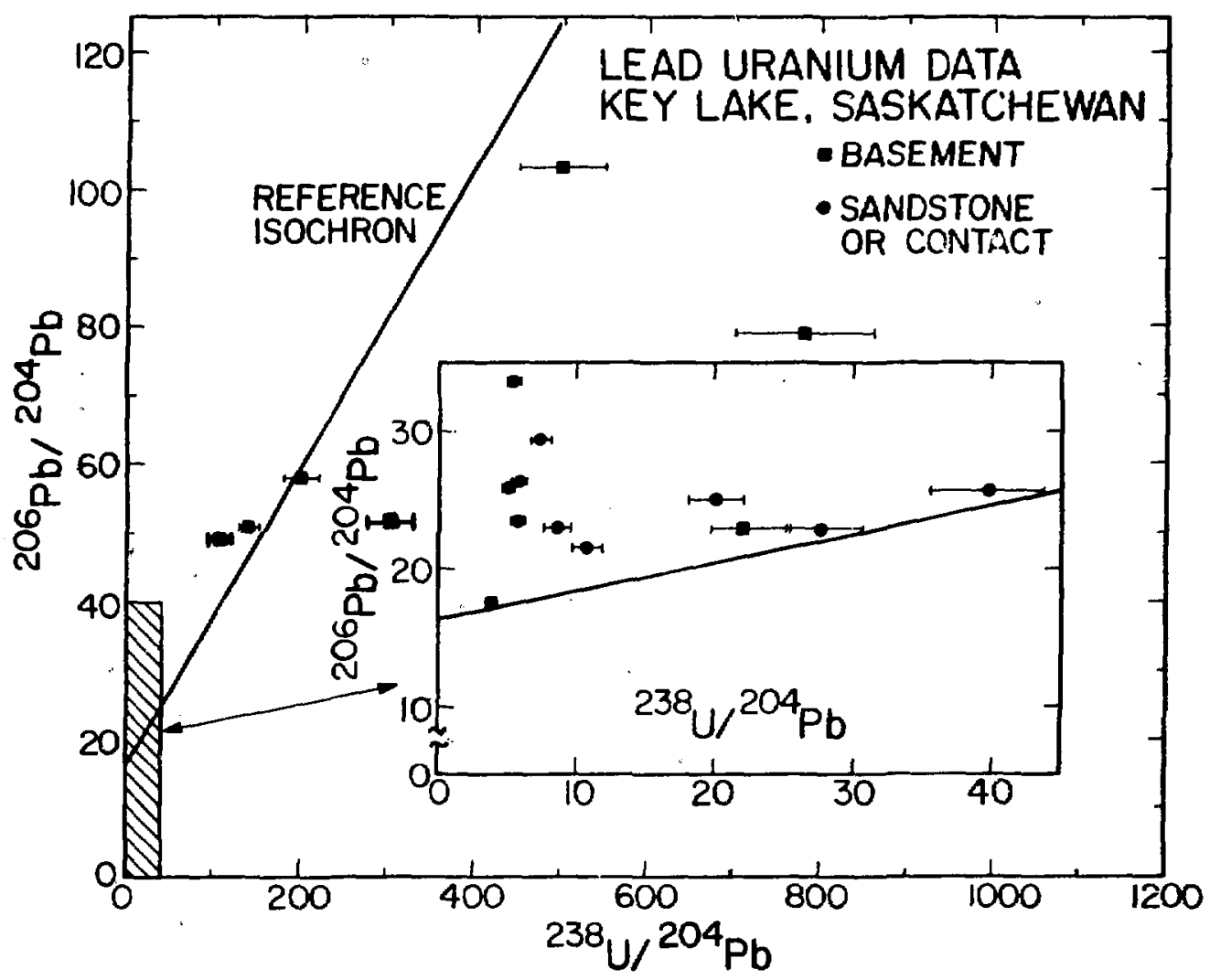

Fig. 3. This ${ }^{238} \mathrm{U}-{ }^{206} \mathrm{~Pb}$ reference isochron was constructed using the initial-lead isotopic ratio and the duration of uranium decay determined from Figure 1. Data that lie on the isochron represent samples that have lost no lead relative to uranium. Those to the left manifest a relative enrichment of lead relative to uranium. Data to the right represent a relative lead deficiency. 
diagram that graphically demonstrates this relationship. The reference isochron shows the covariance of parent and daughter calculated from equation (2) using time and initial lead parameters that are determined by the isochron in Figure 1. Data that lie on this line in Figure 3 are indicative of rocks that have no loss or gain of lead or uranium for $1.3 \times 10^{9}$ years. Two samples from above the unconformity yield data that plot on the isochron. Data to the left of the isochron represent samples that contain more radiogenic lead than could have been generated by the measured quantity of uranium in $1.3 \times 10^{9}$ years. Consequently, rocks that plot in this region must contain lead that was formed elsewhere, or were stripped of a portion of uranium. The remaining eight samples from above the unconformity contain lead and uranium which plot in this portion of Figure 3 . These samples contain relative excesses of lead that range from 2 to 8 times the quantity that is predicted from the uraniam abundance. A similar relationship is observed between thorium and its daughter ${ }^{208} \mathrm{~Pb}$ : The two samples that are concordant with respect to uranium and lead are also concordant in thorium and lead. The remaining seven samples from above the unconformity contain large excesses of ${ }^{208} \mathrm{~Pb}$.

Three of the seven basement rocks do not vary from the isochron within the uncertainties of the measurements. Two of the rocks from 15 meters below the ore are significantly depleted in lead relative to uranium. Another two samples, one taken $5 \mathrm{~km}$ from Key Lake, have relative lead excesses that constitute $20-30 \%$ of the total lead in the rocks. Both of the ore samples that have been analyzed are deficient in lead. Again using the $1.3 \times 10^{9}$ years age, the ore sample $\mathrm{KL}-6$ is depleted in lead by a factor of two, and KL-3 by a factor of seven.

C." Element Migration

There is a consistent pattern of element fractionation in rocks from above the Athabasca unconformity. The majority of samples from this region are enriched in radiogenic lead or depleted in uranium and thorium. Only two do not show this pattern, these are unfractionated with respect to lead and its parent elements. The isotopic systematics cannot distinguish between lead excesses and uranium and thorium deficiencies. However, a comparison of lead abundances in the sandstones suggests that lead was transported to, and deposited in, these rocks: Sample $\mathrm{KL}-12$, the only sandstone that does not contain a relative excess of radiogenic lead, has an absolute abundance of lead that 
is one to two orders of magnitude less than in any of the other sandstones. We conclude that large volumes of rock above the unconformity have been a transport path for a mobile phase and are a repository for lead.

Uranium rich ores are very deficient in radiogenic lead. This deficiency represents an enormous mass of lead that has been transported away from the nineralized rocks. A priori they would appear to be a likely source for the lead found in the overlying sandstones. However, excess lead in the sandstone has isotopic compositions that do not appear to have been produced in the ores. Source rocks for this lead contained two to five times more thorium than uranium. In contrast, the thorium content of the ores must be significantly less than the uranium abundance. Work in progress should help to define the relationship between $\mathrm{Pb}$ deficient ores and $\mathrm{Pb}$ rich rocks.

\section{REFERENCES}

1. Barnes, I. L., Murphy, T. J., Gramlich, J. W., Shields, W. R. (1973), Lead separation by anodic deposition and isotope ratio wass spectrometry of microgram and smaller samples, Anal. Chem. 45, p. 1881-1886.

2. Chen, James (1979), personal communication.

3. Cummings, G. L. and Scott, B. P. (1976) Rb/Sr dating of rocks from the Wollaston Lake Belt, Saskatchewan. Can. J. Earth Sci. 13, p. 355-364.

4. Dahlkamp, Franz J. and Tan, B. (1977) Geology and mineralogy of the Key Lake U-Ni deposits, northern Saskatchewan, Canada., Jones J. J. ed. in Geology mining and extractive processing of uraniun: The Institution of Mining and Matallurgy, p. 145-157.

5. Dahlkamp, Franz J. (1978) Geology appraisal of the Key Lake U-Ni deposits, northern Saskatchewan, Econ. Geol. 73, pp. 1430-1449.

6. Gancarz, A. J. (1979) Chronology of the Cluff Lake uranium deposit, Saskatchewan, Canada, in International Uranium Symposiun on the Pine Creek Geosyncline.

7. Hoeve, Jan and Sibbald, Thomas I. I. (1978) On the genesis of Rabbit Lake and other unconformity-type uraniun deposits in Northern Saskatchewan, Canada, Econ. Geol. 73, pp. 1450-1473.

8. Money, P. L. (1968) The Wollaston fold-belt system, Saskatchewan-Manitoba. Can. J. of Earth Sci. 5, p. 1489-1504.

9. Raemaekers P. P. and Dunn, C. E. (1977) Geology and geochemistry of the eastern wargin of the Athabasca Basin in Dunn, c. c., ed., Uraniu in Saskatchewan: Saskatchewan Geol. Soc. Spec. Pub. 3 p. 297-322. 